\title{
Myrtle berries seeds aqueous extract abrogates chronic alcohol consumption- induced erythrocytes osmotic stability disturbance, haematological and biochemical toxicity
}

\author{
Mohamed-Amine Jabri", Lamjed Marzouki and Hichem Sebai
}

\begin{abstract}
Background: This study examined the effects of chronic alcohol consumption in the rat erythrocytes membrane as well as the involvement of reactive oxygen species and proinflammatory cytokines in its pathogenicity in rats and evaluated the ameliorating effects of myrtle berries seeds aqueous extract (MBSAE).

Methods: Fifty adult male Wistar rats were equally divided into five groups and treated daily for two months as follows: control, ethanol (3 $\mathrm{g} \mathrm{kg}^{-1}$ b.w., p.o.), and ethanol + $\operatorname{MBSAE}\left(25,50\right.$ and $100 \mathrm{mg} \mathrm{kg}^{-1}$, b.w., p.o.).

Results: Exposure of rats to alcohol caused significant changes of some haematological parameters, enhanced erythrocytes hemolysis as well as an overproduction of reactive oxygen species such as $\mathrm{H}_{2} \mathrm{O}_{2}, \mathrm{OH}^{*}$ radical and superoxide anion, hence the increase of lipoperoxidation and the depletion of antioxidant enzymes activity as well as non-enzymatic antioxidant (-SH groups and GSH) levels. On the other hand, ethanol intoxication caused the increase of serum TNFa, IL-8, IL-6 and $1 \mathrm{~L} \beta$, markers of tissue inflammation. However, treatment with MBSAE alleviated all the deleterious effects of alcohol consumption.
\end{abstract}

Conclusions: MBSAE possess active compounds, which exert marked protective effects in chronic alcohol intoxication, possibly by regulating the erythrocytes osmotic stability as well as antioxidant and inflammatory mediators.

Keywords: Alcohol, Osmotic stability, Superoxide anion, Active compounds, Haematological parameters

\section{Background}

The effects of alcohol on health are still a serious public health problem. Chronic alcohol intoxication is responsible for excess morbidity and mortality from cancer $[1,2]$, liver disease $[3,4]$, central or peripheral nervous system damage [5, 6], cardiovascular disease [7] or developmental abnormalities in children exposed in utero $[8,9]$. Ethanol is a small molecule absorbed by simple diffusion. This diffusion is slow at the gastric level and the majority $(70 \%$ to $80 \%$ ) is absorbed in the small intestine (duodenum and

\footnotetext{
* Correspondence: jabri.amino@gmail.com

Laboratoire de Physiologie Fonctionnelle et Valorisation des Bio-Ressources -

Institut Supérieur de Biotechnologie de Béja, Université de Jendouba,

Avenue Habib Bourguiba, B.P. 382 -9000 Béja, Tunisia
}

jejunum) $[10,11]$. The distribution of ethanol is very rapid (distribution half-life of 7 to $8 \mathrm{~min}$ ) [12] to highly vascularized organs such as the brain, lungs and liver. The concentrations in these different organs are very quickly balanced with the blood concentrations [11]. Erythrocytes are the first line of cells affected by alcohol after the gastric mucosa cells. In fact, unmetabolised alcohol exerts direct effects, including hemolysis, and disruption of erythrocyte membranes by increasing fluidity and forming membrane pores $[13,14]$. The production of reactive oxygen species seems to be a determining factor responsible for the erythrocytes membrane destruction observed in excessive alcohol consumers $[15,16]$. Many studies have highlighted the production of free radicals during the metabolism of 
ethanol. These free radicals are at the origin of the lipoperoxidation of membranes and particularly the erythrocyte membranes [17-19]. The products of peroxidation are aldehydes such as malondialdehyde (MDA) and 4-hydroxy2-nonenal (HNE). Unlike free radicals, these aldehydes are stable, diffuse in and out of the cell and can react with targets far from their formation site. They are not the final products of peroxidation, also act as "cytotoxic second messengers" and appear to be involved in most pathophysiological effects associated with oxidative stress [20].

On the other hand, hydrophilic and lipophilic compounds, which act by trapping or suppressing the generation of free radicals, are important in the control of intracellular redox homeostasis. In this context, myrtle (Myrtus communis) L. berries seeds can be used as an alternative treatment against alcohol toxicity and oxidative stress that is associated with him. Owing mainly to its richness in antioxidant and anti-inflammatory compounds such as polyunsaturated fatty acids [21] and phenolic compounds like flavonoids and anthocyanins [22] myrtle berries seeds extracts, are known to exhibit ROS scavenging activities [22], as well as protects against alcoholinduced gastric and duodenal damages [21].

These findings suggest that natural antioxidants may block the erythrocyte membranes destruction during alcohol exposure. Thus, the present study was designed with an aim to investigate the effect of myrtle berries seeds aqueous extract (MBSAE), a potent antioxidant against chronic alcohol-induced lysis of the erythrocyte membrane, haematological parameters disturbance and inflammation.

\section{Methods}

\section{Chemicals}

butylhydroxytoluene (BHT), trichloroacetic acid (TCA), 5,5-Dithio bis(2-nitrobenzoic acid) (DTNB), 2-Thiobarbituric acid (TBA), ethanol, ether, methanol, bovine serum albumin (BSA), bovine catalase, pyrogallol, betaD-2-deoxyribose, Epinephrine, and $\mathrm{NaCl}$ were purchased from Sigma Chemical Co. (Sigma-Aldrich $\mathrm{GmbH}$, Steinheim, Germany).

\section{Myrtle berry seeds aqueous extract preparation}

Myrtle berry seeds were collected in November 2015 from the region of Nefza (North-West of Tunisia). The myrtle berry seeds were dried in an incubator at $50{ }^{\circ} \mathrm{C}$ for $72 \mathrm{~h}$ then ground in an electric mixer (MOULINEX Ovatio 2, FR). The seeds powder was then dissolved in distilled water and incubated at room temperature for $24 \mathrm{~h}$ under magnetic stirring. The sample was centrifuged at $10000 \mathrm{~g}$ for $10 \mathrm{~min}$ and the supernatant was lyophilized, aliquoted and stored at $-80{ }^{\circ} \mathrm{C}$ until use. Chemical composition of MBSAE (Table 1) was determined according to Jabri et al. [22].

\section{Animals and treatment}

Healthy adult male Wistar rats (200-220 g body weight15 weeks old) were purchased from the Pasteur Institute of Tunis and used in accordance with the local ethics committee of Tunis University for the use and care of animals in accordance with the NIH recommendations [23]. They were provided with standard food (standard pellet diet- Badr Utique-TN) and water ad libitum and maintained in animal house at controlled temperature $\left(22 \pm 2{ }^{\circ} \mathrm{C}\right)$ with a $12 \mathrm{~h}$ light-dark cycle.

The animals were divided into five groups of 10 rats each. The first group served as control and received a physiological solution ( $\mathrm{NaCl}, 0.9 \%$, p.o.). The second group was given daily an oral administration of ethanol $(3 \mathrm{~g} / \mathrm{kg}$, b.w., p.o.) prepared as a $35 \%(\mathrm{v} / \mathrm{v})$ solution in 0 . $9 \%(w / v) \mathrm{NaCl}$. The groups 3, 4 and 5 was daily treated with ethanol (3 g/kg, b.w., p.o.) and MBASE (25, 50 and $100 \mathrm{mg} \mathrm{kg}^{-1}$, b.w., p.o.) respectively. At the end of the 2 months treatment period, animals were fasted overnight and sacrificed. The blood sample was collected.

\section{Blood cells count and erythrocytes preparation}

$0.5 \mathrm{~mL}$ of blood sample was firstly collected in EDTA tubes for blood cells count using a haematology analyzer Coulter MAXM (Beckman Coulter, Inc., Fullerton, USA). And the rest was collected in heparinized tubes, whose a part is used to study the erythrocyte osmotic stability and tothe erythrocytes separation. Erythrocytes were isolated by gentle centrifugation $(2000 \mathrm{~g}, 15 \mathrm{~min}$ at $4{ }^{\circ} \mathrm{C}$ ), resuspended in isotonic phosphate buffer $\mathrm{pH} 7.4$, and lysed with a hypotonic solution consisting of $20 \mathrm{mM}$ Tris- $\mathrm{HCl} \mathrm{pH}$ 7.2. Obtained homogenates were after used for biochemical determination of protein, ROS, $\mathrm{SH}$-groups, reduced glutathione and antioxidant enzyme activities as well as MDA levels.

\section{Erythrocytes osmotic stability}

To evaluate the effects of chronic EtOH consumption and MBSAE in a saline solution under physiological conditions on the erythrocytes behavior, the method described by Penha-Silva et al. [24] was used. Briefly, a set of Eppendorf flasks containing $1 \mathrm{~mL}$ of $\mathrm{NaCl}$ solution at concentrations ranging from 0 to $10 \mathrm{~g} / \mathrm{L}$ were pre-incubated for $10 \mathrm{~min}$ at $37{ }^{\circ} \mathrm{C}$. Then, $20 \mu \mathrm{l}$ of whole blood ware added, the samples were afterwards vortexed, incubated for $20 \mathrm{~min}$ and centrifuged at $1300 \times \mathrm{g}$ during $10 \mathrm{~min}$. Absorbance at $540 \mathrm{~nm}$ was measured and converted to percentage hemolysis.

\section{Oxidative stress evaluation}

MDA was estimated using the thiobarbituric acid test [25]. GSH levels were performed according to Sedlak and Lindsay method [26] and Thiol groups (-SH) were performed according to Ellman's method [27]. SOD 
Table 1 Characterisation of phenolic compounds of MBSAE by HPLC-DAD-ESI-MS/MS

\begin{tabular}{|c|c|c|c|c|c|}
\hline compound no. & $t_{R}(\min )$ & $\lambda \max (n m)$ & {$[\mathrm{M}-\mathrm{H}]^{-}$or $[\mathrm{M}-2 \mathrm{H}]^{-}(\mathrm{m} / \mathrm{z})$} & Fragmention $(\mathrm{m} / \mathrm{z})$ & Tentative identification \\
\hline 1 & 6.71 & 254 & 299 & 137 & Hydroxybenzoic acid hexose \\
\hline 2 & 7.94 & $276 ; 515$ & 463 & 301 & Delphinidin-3-O-galactoside \\
\hline 3 & 8.93 & $276 ; 520$ & 463 & 301 & Delphinidin-3-O-glucoside \\
\hline 4 & 9.04 & 354 & 463 & 301 & Quercetin hexoside \\
\hline 5 & 10.33 & $276 ; 515$ & 447 & 301 & Delphinidin-3-O-rhamnoside \\
\hline 6 & 12.27 & $276 ; 515$ & 609 & 301 & Delphinidin rutinoside \\
\hline 7 & 15.95 & $276 ; 520$ & 609 & 301 & Delphinidin-3- (6 coumaroyl)-glucoside \\
\hline 8 & 17.25 & $278 ; 524$ & 493 & 315 & Petunidin-3-O-glucoside \\
\hline 9 & 20.38 & $278 ; 525$ & 655 & 315 & Petunidin diglucoside \\
\hline 10 & 29.25 & $278 ; 525$ & 563 & 315 & Petunidin malonylglucoside \\
\hline 11 & 30.66 & 525 & 621 & 315 & Petunidin-3-O-rutinoside \\
\hline 12 & 30.74 & $278 ; 355$ & 447 & 315 & Isorhamnetin-O-pentoside \\
\hline 13 & 30.78 & $276 ; 516$ & 615 & 299 & Peonidin sambubioside \\
\hline 14 & 39.90 & 351 & 461 & 315 & Isorhamnetin-O-rhamnoside \\
\hline 15 & 39.94 & $282 ; 527$ & 511 & 331 & Malvidin-O-galactoside \\
\hline 16 & 41.07 & $282 ; 527$ & 511 & 331 & Malvidin-O-glucoside \\
\hline 17 & 44.04 & $276 ; 516$ & 641 & 299 & Peonidin diglucoside \\
\hline 18 & 69.95 & $278 ; 525$ & 461 & 331 & Petunidin methyl pentose \\
\hline
\end{tabular}

activity was measured according to the method described by Misra and Fridovich [28]. CAT activity was estimated using Aebi's method [29]. GPx activity was determined according to the method described by Flohé and Günzler [30]. Finally, the protein content was determined according to Hartree [31] which is a slight change of the Lowry method.

\section{Measurement of ROS production}

The intestine $\mathrm{H}_{2} \mathrm{O}_{2}$ level was performed according to Dingeon et al. [32]. Briefly, in the presence of peroxidase, the hydrogen peroxide reacts with p-hydroxybenzoic acid and 4-aminoantipyrine leading to a quantitative formation of a quinoneimine which has a pink color detected at $505 \mathrm{~nm}$.

The hydroxyl radical level was determined using Payá et al. method [33]. Briefly, after oxidation of deoxyribose by hydroxyl radical generated by the $\mathrm{Fe}^{3}+$-ascorbate-EDTA$\mathrm{H}_{2} \mathrm{O}_{2}$ pathway and incubation with erythrocytes homogenate at $37{ }^{\circ} \mathrm{C}$ for one hour, the reaction mixture was stopped by adding of TCA (2.8\%) and TBA (1\%) and boiled at $100{ }^{\circ} \mathrm{C}$ for $20 \mathrm{~min}$. Changes in absorbance were recorded at $532 \mathrm{~nm}$ against blank containing deoxyribose and buffer.

Superoxide radical was estimated according to Marklund and Marklund [34] with slight changes. Briefly, erythrocytes homogenates were incubated in Tris- $\mathrm{HCl}$ buffer, and then pyrogallol was added to the reaction mixture which will be incubated at $25{ }^{\circ} \mathrm{C}$ for fourminutes. The reaction has been stopped by $\mathrm{HCl}$ addition and absorbance was read at $420 \mathrm{~nm}$ against the blank.
Assessment of cytokines: TNFa, IL-8, IL-6 and 1 L-1 $\beta$ in plasma

Cytokines (TNF $\alpha$, IL-8, IL-6 and 1L $\beta$ ) levels were determined in the plasma samples using standard sandwich enzyme-linked immunosorbent assay (ELISA) kit according to the manufacturer's instruction and expressed in pg per mg of proteins.

\section{Statistical analysis}

All the data were expressed as mean \pm standard error of the mean (S.E.M). Differences between the experimental groups were assessed by one-way ANOVA followed by Duncan's test. Values were considered statistically significant when $p<0.05$.

\section{Results}

Effect of chronic EtOH consumption and MBSAE on erythrocytes osmotic stability

As shown in Fig. 1, chronic ethanol intoxication caused a weakening of the erythrocyte resistance against hypotonic shock caused by different concentrations of sodium chloride compared to the control group as shown by the shift to the right of the hemolysis curve (Fig. 1a). However, MBSAE (25, 50 and $100 \mathrm{mg} \mathrm{kg}^{-1}, b$. w. p.o.) significantly and dose-dependently increased the resistance of red blood cells, hence the inhibition of hemolytic activity caused by chronic consumption of ethanol and thus the inhibition of hemoglobin release. 

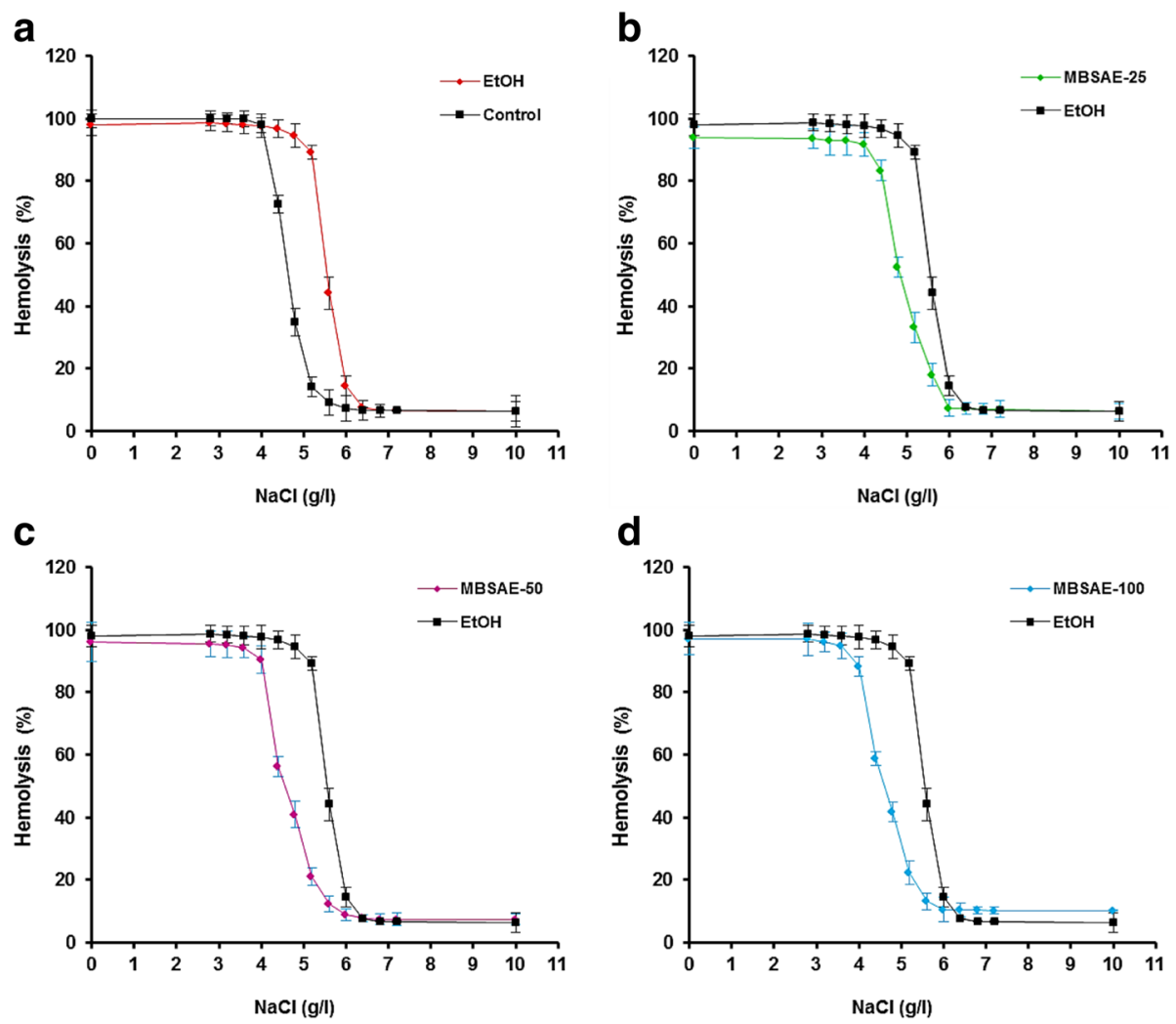

Fig. 1 Effect of myrtle berries seeds aqueous extract (MBSAE) on chronic EtOH-induced disturbance in erythrocytes osmotic stability in physiological-like saline solution at $37^{\circ} \mathrm{C}$. a Osmotic stability curve of control rat erythrocytes compared to the ethanol (3 g kg-1 b.w., p.o./60 days) intoxicated groups. b Osmotic stability curve of MBSAE (25 mg kg-1, b.w., p.o.) treated rat erythrocytes compared to the ethanol (3 g/kg b.w/60 days) intoxicated groups. c Osmotic stability curve of MBSAE (50 mg kg-1, b.w., p.o.) treated rat erythrocytes compared to the ethanol (3 g/kg b.w/60 days) intoxicated groups. d Osmotic stability curve of MBSAE (100 mg kg-1, b.w., p.o.) treated rat erythrocytes compared to the ethanol (3 g/kg b.w/60 days) intoxicated groups. The data are expressed as mean \pm S.E.M. $(n=10)$

\section{Effect of chronic EtOH consumption and MBSAE on haematological parameters changes}

Table 2 shows the data of comparing haematological parameters. Alcohol consumption during two months caused a significant decrease of hemoglobin concentration
$(\mathrm{Hb})$, red blood cells number (RBC), mean corpuscular hemoglobin $(\mathrm{MCH})$, hematocrit value $(\mathrm{Ht})$, mean corpuscular hemoglobin concentration $(\mathrm{MCHC})$ and platelets (PIt) number, on the other hand, a considerable increase in the mean corpuscular volume (MCV) level and white

Table 2 Effect of myrtle berries seeds aqueous extract (MBSAE) on chronic EtOH-induced haematological parameters changes

\begin{tabular}{|c|c|c|c|c|c|}
\hline \multirow[t]{2}{*}{ Parameters } & \multicolumn{5}{|c|}{ Experimental groups } \\
\hline & Control & $\mathrm{EtOH}$ & $\mathrm{EtOH}+\mathrm{MBSAE}-25$ & $\mathrm{EtOH}+\mathrm{MBSAE}-50$ & $\mathrm{EtOH}+\mathrm{MBSAE}-100$ \\
\hline RBC count $\left(10^{6} / \mu \mathrm{l}\right)$ & $7.88 \pm 0.76$ & $6.47 \pm 0.28$ & $7.33 \pm 0.41$ & $7.47 \pm 0.38$ & $7.55 \pm 0.77$ \\
\hline $\mathrm{Hb}(\mathrm{g} / \mathrm{dl})$ & $14.63 \pm 0.44$ & $9.22 \pm 0.21^{*}$ & $12.56 \pm 0.32^{\#}$ & $13.70 \pm 0.88^{\#}$ & $14.04 \pm 0.90^{\#}$ \\
\hline $\mathrm{Ht}(\%)$ & $47.58 \pm 1.71$ & $39.66 \pm 1.44^{*}$ & $41.72 \pm 1.14$ & $43.58 \pm 1.77^{\#}$ & $45.36 \pm 2.16^{\#}$ \\
\hline $\mathrm{MCV}\left(\mathrm{mm}^{3} / \mathrm{RBC}\right)$ & $53.61 \pm 2.43$ & $68.33 \pm 2.71^{*}$ & $61.44 \pm 3.07$ & $58.33 \pm 2.81^{\#}$ & $55.44 \pm 2.09^{\#}$ \\
\hline $\mathrm{MCH}(\mathrm{pg} / \mathrm{RBC})$ & $21.73 \pm 1.51$ & $19.39 \pm 1.66$ & $20.19 \pm 2.39$ & $20.08 \pm 2.80$ & $21.09 \pm 2.26$ \\
\hline $\mathrm{MCHC}(\mathrm{g} / \mathrm{dl})$ & $35.09 \pm 1.12$ & $30.22 \pm 1.66^{*}$ & $32.14 \pm 1.85$ & $34.12 \pm 2.63^{\#}$ & $34.80 \pm 2.47^{\#}$ \\
\hline Plt $\left(10^{3} / \mu \mathrm{l}\right)$ & $741.70 \pm 73.82$ & $222.31 \pm 72.88^{*}$ & $620.91 \pm 66.66^{\#}$ & $681.15 \pm 68.32^{\#}$ & $711.06 \pm 77.12^{\#}$ \\
\hline $\operatorname{WBC}\left(10^{3} / \mu \mathrm{l}\right)$ & $10.31 \pm 0.45$ & $17.21 \pm 2.33^{*}$ & $13.51 \pm 0.89^{\#}$ & $12.77 \pm 1.08^{\#}$ & $10.81 \pm 0.74^{\#}$ \\
\hline
\end{tabular}

Animals were daily treated with various doses of the $\operatorname{MBSAE}\left(25,50\right.$ and $100 \mathrm{mg} \mathrm{kg}^{-1}$, b.w., p.o.) or vehicle $(\mathrm{NaCl} 0.9 \%)$ before ethanol $\left(30 \%, \mathrm{v} / \mathrm{v}, 10 \mathrm{~mL} \mathrm{~kg}{ }^{-1}\right.$, b.w.) intoxication during two months. The data are expressed as mean \pm S.E.M. $(n=10), *: p<0.05$ compared to control group and \#: $p<0.05$ compared to EtOH group RBC Red blood cell, $M C V$ mean corpuscular volume, $M C H$ mean corpuscular hemoglobin, $H b$ Hemoglobin, Ht Hematocrit, MCHC mean corpuscular hemoglobin concentration, Plt Platelet and WBC white blood cells 
blood cells number (WBC) was marked. MBSAE treatment with the three increasing doses reversed the above changes of haematological parameters to near to baseline levels.

\section{Effect of chronic EtOH consumption and MBSAE on erythrocytes lipid peroxidation}

As expected, the $\mathrm{EtOH}$ group was characterized by a significant increase in erythrocytes MDA level, reflect of lipid peroxidation. While treatment with myrtle berries seeds aqueous extract $\left(25,50\right.$ and $100 \mathrm{mg} \mathrm{kg}^{-1}$, b.w., p.o.) significantly decreased the erythrocytes lipid peroxidation $(12.27 \pm 1.44 \mathrm{nmol} / \mathrm{mg}$ protein for the high dose) compared to the EtOH control group $(28.06 \pm 2.59 \mathrm{nmol} / \mathrm{mg}$ protein $)$ (Table 3).

\section{Effect of chronic EtOH consumption and MBSAE on} erythrocytes thiol groups and reduced glutathione

Erythrocytes thiol groups and reduced glutathione levels were decreased in EtOH-treated group as compared with respective controls. The animals treated with myrtle berries seeds aqueous extract exhibited significant and dose-dependant restoration in - $\mathrm{SH}$ groups and GSH (Table 3) levels.

\section{Effect of chronic EtOH consumption and MBSAE on erythrocytes antioxidant enzymes}

The effect of aqueous extract of myrtle seeds on antioxidant enzymes activity in ethanol intoxicated rats is summarized in Table 3. Chronic alcohol consumption led to a significant decrease in the SOD, CAT and GPx activities in the erythrocytes as compared to the control group. While, treatment with $\operatorname{MBSAE}(25,50$ and $100 \mathrm{mg} \mathrm{kg}-1$, b.w., p.o.) significantly increased the antioxidant enzymes activity towards the normal value $(P<0.05)$ thus demonstrating the significant protective effect of MBSAE on chronic ethanol consumption-induced erythrocytes injuries.

\section{Effect of chronic EtOH consumption and MBSAE on erythrocytes ROS production}

The effects of the EtOH and MBSAE on erythrocytes reactive oxygen species were studied, and the results were summarized in Fig. 2. The administration of ethanol to rats during two months produced elevated erythrocytes oxidative stress, which was demonstrated by a significant increase in the hydrogen peroxide, hydroxyl radical and superoxide anion levels. MBSAE treatment showed protective effects against erythrocyte ROS overload induced by chronic ethane treatment, due to its ROS scavenging activities.

\section{Effect of chronic EtOH consumption and MBSAE on serum cytokines levels}

Enzyme-linked immunosorbent assay analysis was used to investigate the effects of EtOH and MBSAE (25, 50 and $100 \mathrm{mg} \mathrm{kg}{ }^{-1}$, b.w., p.o.) on serum TNF $\alpha$, IL-8, IL-6 and $1 \mathrm{~L} \beta$ levels (Fig. 3). Chronic alcohol consumption caused severe tissue inflammation, demonstrated by higher levels of plasma cytokines compared to the control. Nevertheless, MBSAE treatment significantly and dose dependently abolished the $\mathrm{EtOH}$-induced inflammation.

\section{Discussion}

The present study was undertaken to evaluate the effect of myrtle berries seeds aqueous extract against chronic ethanol consumption induces erythrocytes injuries and blood parameters changes.

We firstly showed that the exposure of rats to ethanol consumption during two months induced haematological changes by a decrease of $\mathrm{Hb}, \mathrm{RBC}, \mathrm{MCH}, \mathrm{Ht}$, $\mathrm{MCHC}$ and platelets number as well as increase in mean corpuscular volume level and white blood cells number. Indeed, the decrease of RBCs, $\mathrm{Hb}$ and $\mathrm{Ht}$ might be due to an inhibition of erythropoiesis and hemoglobin synthesis as well as to the increase in the level of erythrocytes destruction [35]. The increase in mean corpuscular volume and WBC number is related to the activation of defense and immune systems and showed that there were inflammations in the tissues [18]. The treatment with myrtle berries seeds aqueous extract returned these haematological parameters to near normal. Ethanolinduced blood parameters changes have been shown to be inhibited by many plant extracts such as chamomile [18] and Opuntia ficus indica juice [19].

Table 3 Effect of myrtle berries seeds aqueous extract (MBSAE) on chronic EtOH-induced erythrocytes oxidative stress

\begin{tabular}{lllllll}
\hline Treatment & MDA & SOD & CAT & GPx & -SH groups & GSH \\
\hline Control & $10.23 \pm 1.12$ & $37.93 \pm 3.65$ & $44.47 \pm 4.42$ & $26.48 \pm 2.57$ & $166.73 \pm 9.84$ & $44.84 \pm 4.66$ \\
EtOH & $28.06 \pm 2.59^{*}$ & $22.16 \pm 2.09^{*}$ & $26.28 \pm 2.08^{*}$ & $14.31 \pm 1.65^{*}$ & $73.66 \pm 6.53^{*}$ & $19.69 \pm 3.18^{*}$ \\
EtOH + MBSAE-25 & $19.98 \pm 1.31^{\#}$ & $29.38 \pm 2.17^{\#}$ & $35.60 \pm 2.56^{\#}$ & $19.81 \pm 1.42^{\#}$ & $101.14 \pm 6.33^{\#}$ & $28.78 \pm 4.11^{\#}$ \\
EtOH + MBSAE-50 & $14.47 \pm 1.75^{\#}$ & $32.60 \pm 2.229^{\#}$ & $38.73 \pm 2.27^{\#}$ & $21.37 \pm 0.72^{\#}$ & $122.47 \pm 7.11^{\#}$ & $33.47 \pm 3.18^{\#}$ \\
EtOH + MBSAE-100 & $12.27 \pm 1.44^{*}$ & $35.52 \pm 2.83^{\#}$ & $41.72 \pm 3.58^{\#}$ & $24.64 \pm 1.81^{\#}$ & $147.18 \pm 8.41^{\#}$ & $38.82 \pm 3.64^{\#}$
\end{tabular}

Animals were daily treated with various doses of the $\operatorname{MBSAE}\left(25,50\right.$ and $100 \mathrm{mg} \mathrm{kg}^{-1}$, b.w., p.o.) or vehicle $(\mathrm{NaCl} 0.9 \%)$ before ethanol $\left(30 \%, \mathrm{v} / \mathrm{v}, 10 \mathrm{~mL} \mathrm{~kg}{ }^{-1}, \mathrm{~b} . w.\right)$ intoxication during two months

MDA nmol of MDA/mg protein, SOD units/mg protein, CAT $\mu$ mol of $\mathrm{H}_{2} \mathrm{O}_{2}$ consumed $/ \mathrm{min} / \mathrm{mg}$ protein, GPx nmol GSH oxidized/min/mg protein, $-\mathrm{SH}$ groups $\mu \mathrm{mol} / \mathrm{mg}$ protein, $\mathrm{GSH} \mathrm{nmol}$ of $\mathrm{GSH} / \mathrm{mg}$ protein

The data are expressed as mean \pm S.E.M. $(n=10)$, * $p<0.05$ compared to control group and \#: $p<0.05$ compared to EtOH group 


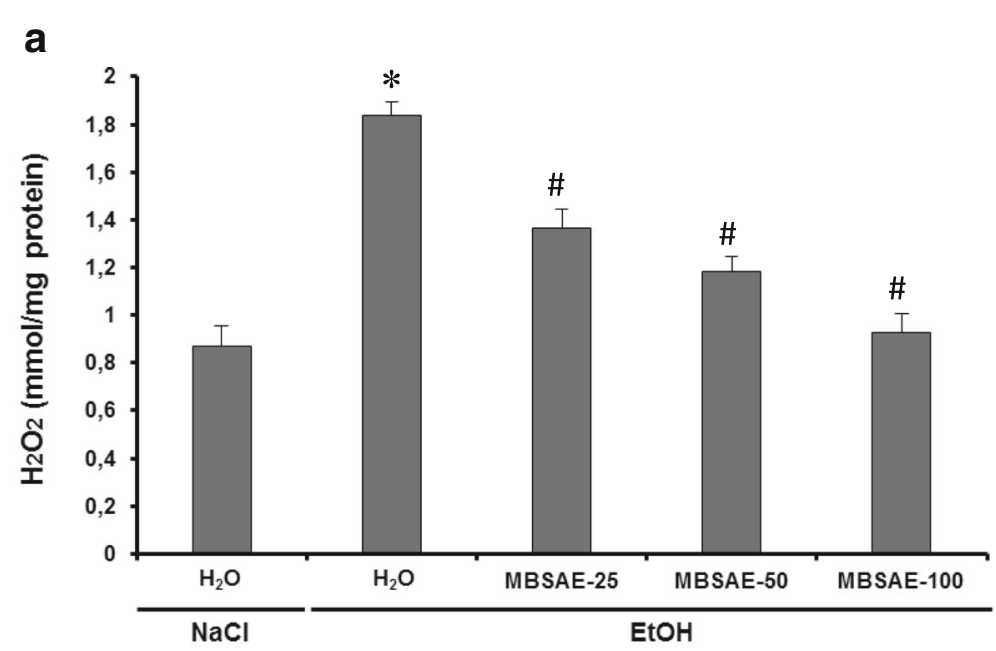

b

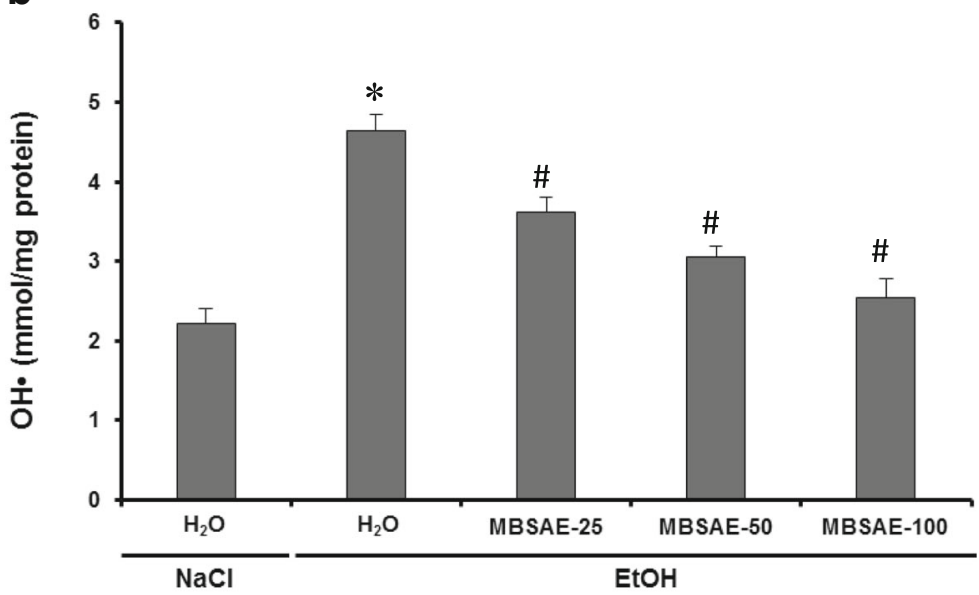

C

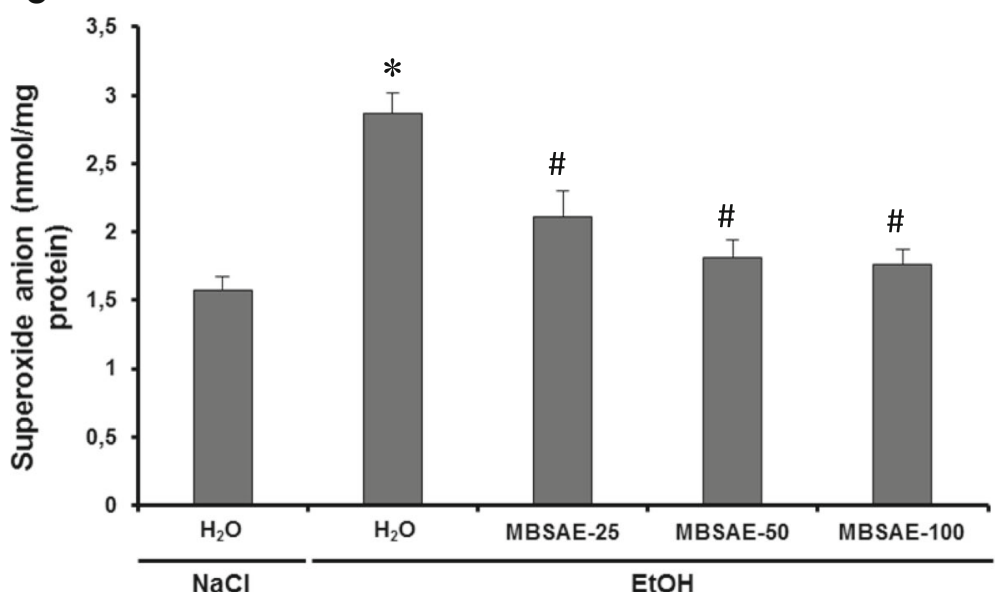

Fig. 2 Effect of myrtle berries seeds aqueous extract (MBSAE) on chronic EtOH-induced disturbance in erythrocytes hydrogen peroxide (a),

Hydroxyl radical (b) and superoxide anion (c). Animals were daily treated with various doses of the MBSAE (25, 50 and 100 mg kg ${ }^{-1}$, b.W., p.o.) or vehicle $(\mathrm{NaCl} 0.9 \%)$ before ethanol $\left(30 \%, v / \mathrm{v}, 10 \mathrm{~mL} \mathrm{~kg}{ }^{-1}\right.$, b.w.) intoxication during two months. The data are expressed as mean \pm S.E.M. $(n=10)$, *: $p<0.05$ compared to control group and \#: $\mathrm{p}<0.05$ compared to EtOH group

On the other hand, we demonstrated that chronic ethanol intoxication acts on the osmotic stability of erythrocytes and causes their destruction by releasing their contents. In fact, the process of hemolysis is an irreversible phenomenon in which red blood cells are destroyed and release their content. Several factors are 

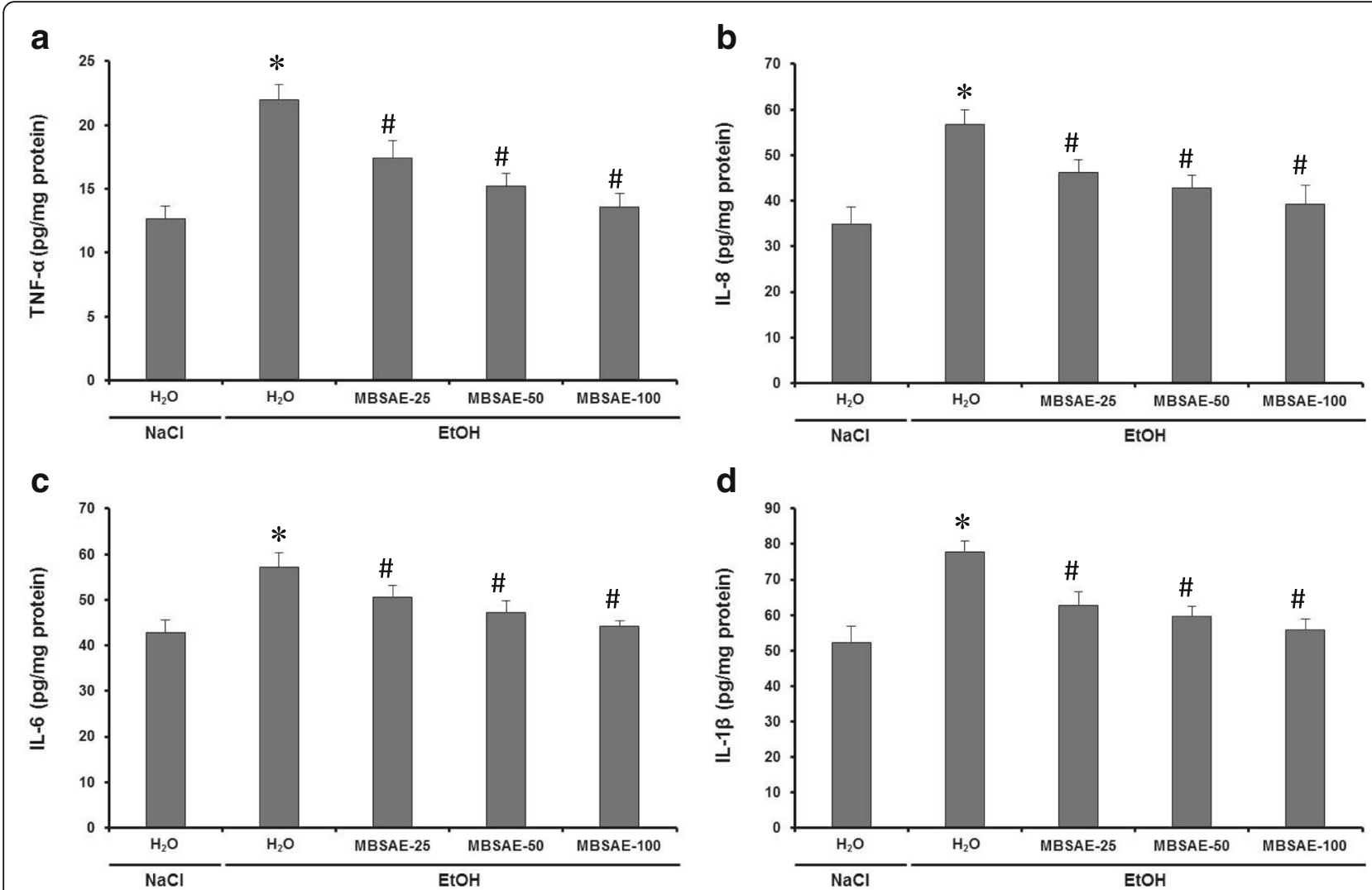

Fig. 3 Effect of myrtle berries seeds aqueous extract (MBSAE) on chronic EtOH-induced disturbance in serum TNF-a (a), IL-8 (b), IL-6 (c) and IL-1 $\beta$ (d). Animals were daily treated with various doses of the $\operatorname{MBSAE}\left(25,50\right.$ and $100 \mathrm{mg} \mathrm{kg}^{-1}$, b.w., p.o.) or vehicle (NaCl 0.9\%) before ethanol $\left(30 \%, v / v, 10 \mathrm{~mL} \mathrm{~kg}^{-1}\right.$, b.w.) intoxication during two months. The data are expressed as mean \pm S.E.M. $(n=10)$, *: $p<0.05$ compared to control group and \#: $p<0.05$ compared to EtOH group

involved in hemolysis process citing, plasma, the anatomical state of the circulatory system and the functional status of the phagocytic mononuclear system [16, 36]. The haemolytic effect of a hypotonic solution is related to an excessive accumulation of fluid in the cell $[37,38]$ and attributed to its interaction with the sterols of the erythrocyte membrane which induces an increase of the membrane permeability and a movement of the ions: entry of $\mathrm{Na}^{+}$and $\mathrm{H}_{2} \mathrm{O}$, exit of $\mathrm{K}^{+}$, the membrane bursts, allowing the release of hemoglobin [39, 40]. Ethanol is also capable of promoting the lysis of erythrocytes, which has been attributed to the denaturing of membrane proteins [41]. However, an abundant literature is available concerning the involvement of ethanol in the lysis of the erythrocyte membrane $[19,24,41]$.

Secondly, we showed in this study that MBSAE $(25,50$ and $100 \mathrm{mg} \mathrm{kg}^{-1}$, b.w., p.o.) effectively protected against erythrocyte lysis induced by chronic alcohol consumption and strengthens the resistance of red blood cells, thus testifying to a powerful anti-hemolytic activity. The lysis of the erythrocyte membrane has also been shown to be attenuated by many plant extracts such as Salvia verbenaca [42], Allium rotundum [43] and Cyperus rotundus [44] as well as by some pharmacological agents such as pyrrole carboxylic acids [45] and S-triazole-2-thiols [46].

In addition, taking alcohol for two months caused oxidative damage at the erythrocyte, manifested by the increase in the MDA level, an end product of lipid peroxidation and decreased the antioxidant enzyme activities such as SOD, CAT and GPx. Chronic alcoholism also induced a decrease of reduced glutathione (GSH) and sulphhydrils (-SH) groups levels. More importantly, myrtle seeds protect, significantly and dose dependently against all erythrocyte oxidative injuries induced by ethanol and return the values similar to those found in non-alcoholic animals at the highest dose. However, it is well established that induction of oxidative stress is part of the mechanisms of toxicity of alcohol [17]. If ethanol is not metabolized, it is able to trap the radical $\mathrm{OH}^{*}$; on the other hand, following its metabolism, it produces the reactive oxygen species (ROS) [47]. In addition, these ROSs contribute to its toxicity by triggering oxidative stress, but also accelerate its metabolism by the synthesis of the hydroxyethyl radical [48]. The particularity of ethanol-induced oxidative stress also lies in its ability to generate favorable conditions for the development of 
oxidative stress such as hypoxia, endotoxemia and cytokine release [17].

Erythrocytes are considered the major target of free radicals because their high polyunsaturated fatty acids (PUFAs) content, such as linoleic acid and arachidonic acid $[49,50]$. In our study we showed that rats treated with ethanol showed marked higher erythrocytes ROS such as $\mathrm{H}_{2} \mathrm{O}_{2}$, hydroxyl radical and superoxide anion levels than all groups. Indeed, many studies have highlighted the production of ROS during the ethanol metabolism. These ROS are at the origin of the lipoperoxidation of the erythrocytes membranes. They may be derived from microsomal activity, mitochondrial respiratory chain, or oxidation of acetaldehyde by xanthine oxidase $[51,52]$. In addition, the rate of hemolysis has been shown to be much higher when erythrocytes are treated with hydrogen peroxide [53]. This could be attributed to the oxidative nature of hydrogen peroxide and its ability to destroy the cell membrane and consequently the release of hemoglobin from cells. Hydrogen peroxide can also cause hydroxyl radical toxicity in provoking haem degradation of hemoglobin thus releasing $\mathrm{Fe}^{2+}$ ions which generates by the Fenton reaction the $\mathrm{OH}^{*}$ radical, more powerful thus contributing to lipid peroxidation $[53,54]$.

Moreover, we have shown that the antihemolitic activity of myrtle berries seeds aqueous extract is attributed in part to its ROS scavenging activity. Indeed, The MBSAE treatment has effectively inhibited the erythrocyte $\mathrm{H}_{2} \mathrm{O}_{2}, \mathrm{OH}^{*}$ radical and superoxide anion overload.

Otherwise, the HPLC-PDA-ESI-MS/MS analysis of MBSA revealed the presence 18 phenolic compounds, especially phenolic acids such as hydroxybenzoic acid hexose, flavonoids, like quercetin hexoside, isorhamnetin-O-pentoside and isorhamnetin-O-rhamnoside as well as anthocyanins, such as peonidin sambubioside, malvidin-O-galactoside, malvidin-O-glucoside, delphinidin3-O-galactoside, delphinidin-3-O-glucoside, delphinidin-3-O-rhamnoside, delphinidin rutinoside, petunidin diglucoside, petunidin malonylglucoside, petunidin-3$O$-rutinoside, delphinidin-3- (6 coumaroyl)-glucoside, peonidin diglucoside, petunidin-3-O- glucoside and petunidin methyl pentose $[22,55]$. Indeed, these antioxidant molecules can reduce the toxicity of alcohol because they have a structure that allows them to trap free radicals by neutralizing them, which prevents ROS from reaching their biological targets [56]. In addition, the flavonoids that are identified in the MBSAE effectively inhibit have been shown to effectively inhibit the neutrophil myeloperoxidase (MPO), enzyme which use hydrogen peroxide $\left(\mathrm{H}_{2} \mathrm{O}_{2}\right)$ to catalyze the production of the potent oxidants hypobromous acid ( $\mathrm{HOBr})$, hypothiocyanous acid (HOSCN) and hypochlorous acid (HOCl) [22]. Phenolic compounds identified in MBSAE has also inhibited the $\mathrm{H}_{2} \mathrm{O}_{2}$ and $\mathrm{OH}$ - radical produced by human neutrophils [22].

More importantly, our data showed also that MBSAE treatment abolished chronic EtOH-induced inflammation. Furthermore, clinical studies have shown that excessive alcohol users have higher levels of serum TNF $\alpha$, interleukin-1 and interleukin-6 than controls [57, 58]. IL-8 is a chemotactic cytokine for neutrophils [59]. The main stimuli of IL- 8 secretion are TNF $\alpha$, IL-1 and endotoxin. Several studies have shown that TNF $\alpha$, IL-8, IL-6 and $1 \mathrm{~L} \beta$ are involved in the pathogenesis of alcoholic lesions of liver [60], brain [6] and stomach [61].

On the other hand, in a previous work we showed that MBSAE is very rich in polyunsaturated fatty acids (PUFAs), of which linoleic acid (80.78\%) and oleic acid (6.34\%) are the 2 major compounds [21]. in fact, polyunsaturated n-3 fatty acids exert its antiinflammatory effect by the competitive inhibition of eicosanoild production from arachidonic acid. In addition, they inhibit the production and expression of proinflammatory cytokines, metalloproteinases [62]. In addition, omega-3 PUFAs intake reduces the proportion of arachidonic acid, resulting in decreased production of prostaglandin PGE-2. These PUFAs also inhibit the production of TNF- $\alpha$ and several interleukins by monocytes, macrophages or endothelial cells [63]. In this context, myrtle berries seeds aqueous extract (MBSAE) has been widely studied for their protective effect against duodenal [21], esophageal [64] and colon [22] inflammation.

In addition, several studies have shown that the chronic consumption of alcohol causes a significant fall of mitochondrial membrane potential $[65,66]$, which leads to cellular necrosis [67]. Moreover, the decrease in the potential of the mitochondrial membranes causes the opening of the ports of the transitions and permeability, these pores are generally opened by the ROS and cytokines [66]. In contrast, the ROS scavenging activity of MBSAE and its ability to inhibit proinflammatory cytokines restore the mitochondrial membrane potential and protect the cells against apoptosis and necrosis associated with the alteration of mitochondrial activities by alcohol consumption.

\section{Conclusion}

In conclusion, alcohol consumption during two months induced overload of reactive oxygen species and the disturbance of erythrocytes redox balance leading to the haematological parameters change and lysis of the erythrocyte membrane as well as increased levels of TNF $\alpha$, IL-8, IL- 6 and 1L $\beta$, markers of tissue inflammation. But, the MBSAE offered significant protection against the chronic toxicity of $\mathrm{EtOH}$ by restoring these parameters to normal, which may be attributed to its chemical composition and their anti-inflammatory and ROS scavenging activities. 


\section{Abbreviations}

CAT: Catalase; EtOH: Ethanol; GPx: Glutathione peroxidase; GSH: Reduced glutathione; H2O2: Hydrogen peroxide; MBSAE: Myrtle berries seeds aqueous extract; MDA: Malondialdehyde; ROS: Reactive oxygen species; SH: Sulfhydril groups; SOD: Superoxide dismutase

\section{Acknowledgements}

Financial support of the Tunisian Ministry of Higher Education and Scientific Research is gratefully acknowledged. Financial disclosures: none declared.

\section{Funding}

This review was written independently; no company or institution supported it financially.

\section{Availability of data and materials}

Data sharing not applicable to this article as no datasets were generated or analysed during the current study.

\section{Authors' contributions}

$\mathrm{M}-\mathrm{AJ}$ and $\mathrm{SH}$ designed the study and carried out the biochemical analyses. $\mathrm{M}-\mathrm{AJ}$ and HS performed the statistical analysis and drafted the manuscript with contributions from LM. All authors read and approved the final manuscript.

\section{Ethics approval and consent to participate}

All procedures on animals in this study were compiled with the $\mathrm{NIH}$ recommendations for the use and care of animals.

\section{Consent for publication}

The authors declare that they agree to publish the paper.

\section{Competing interests}

The authors declare that they have no competing interests.

\section{Publisher's Note}

Springer Nature remains neutral with regard to jurisdictional claims in published maps and institutional affiliations.

\section{Received: 11 January 2018 Accepted: 13 April 2018}

\section{Published online: 23 April 2018}

\section{References}

1. Gu S, Nguyen BN, Rao S, Li S, Shetty K, Rashid A, Shukla V, Deng CX, Mishra L, Mishra B. Alcohol, stem cells and cancer. Genes Cancer. 2017:8:695-700.

2. Wang PL, Xiao FT, Gong BC, Liu FN. Alcohol drinking and gastric cancer risk: a meta-analysis of observational studies. Oncotarget. 2017;8:99013-23.

3. Wong NA, Rae F, Simpson KJ, Murray GD, Harrison DJ. Genetic polymorphisms of cytochrome P4502E1 and susceptibility to alcoholic liver disease and hepatocellular carcinoma in a white population : a study and literature review, including metaanalysis. Mol Pathol. 2000;53:88-93.

4. Osna NA. Donohue TM Jr, Kharbanda KK. Alcoholic liver disease: pathogenesis and current management. Alcohol Res. 2017:38:147-61.

5. Guggenmos M, Schmack K, Sekutowicz M, Garbusow M, Sebold M, Sommer C, Smolka MN, Wittchen HU, Zimmermann US, Heinz A, Sterzer P. Quantitative neurobiological evidence for accelerated brain aging in alcohol dependence. Transl Psychiatry. 2017;7:1279.

6. Tiwari V, Chopra K. Resveratrol abrogates alcohol-induced cognitive deficits by attenuating oxidative-nitrosative stress and inflammatory cascade in the adult rat brain. Neurochem Int. 2013:62:861-9.

7. Piano MR. Alcohol's effects on the cardiovascular system. Alcohol Res. 2017:38:219-41.

8. Glendinning Jl, Tang J, Morales Allende AP, Bryant BP, Youngentob L, Youngentob SL. Fetal alcohol exposure reduces responsiveness of taste nerves and trigeminal chemosensory neurons to ethanol and its flavor components. J Neurophysiol. 2017;118:1198-209.

9. Yuan H, Zhang W, Li H, Chen C, Liu H, Li Z. Neuroprotective effects of resveratrol on embryonic dorsal root ganglion neurons with neurotoxicity induced by ethanol. Food Chem Toxicol. 2013:55:192-201.

10. Wagner JG. Properties of the Michaelis-Menten equation and its integrated form which are useful pharmacokinetics. J Pharmacokinet Biopharm. 1973;1:103-21.
11. Wilkinson PK. Pharmacokinetics of ethanol: a review. Alcohol Clin Exp Res. 1980:4:6-21

12. Jones AW, Hahn R, Stalberg HP. Distribution of ethanol and water between plasma and whole blood; inter and intra individual variations after administration of ethanol by intravenous infusion. Scand J Clin Lab Invest. 1990;50:775-80.

13. Lahajnar G, Macek P, Smid P, Zupancic I. Ethanol and acetonitrileinduced inhibition of water diffusional permeability across bovine red blood cell membrane. Biochim Biophys Acta. 1995;1235:437-42.

14. Padmini E, Sundari BT. Erythrocyte glutathione depletion impairs resistance to haemolysis in women consuming alcohol. J Clin Biochem Nutr. 2008:42:14-20.

15. Tyulina OV, Huentelman MJ, Prokopieva VD, Boldyrev AA, Johnson P. Does ethanol metabolism after erythrocyte hemolysis? Biochim Biophys Acta. 2000;1535:69-77.

16. Falcioni G, Cincolà G, Brunori M. Glutathione peroxidase and oxidative hemolysis in trout red blood cells. FEBS Lett. 1987:221:355-8.

17. Sergent O, Griffon B, Cillard P, Cillard J. Alcool et stress oxydatif. Pathol Biol. 2001:49:689-95.

18. Jabri MA, Sani M, Rtibi K, Marzouki L, El-Benna J, Sakly M, Sebai H. Chamomile decoction extract inhibits human neutrophils ROS production and attenuates alcohol-induced haematological parameters changes and erythrocytes oxidative stress in rat. Lipids Health Dis. 2016;15:65.

19. Alimi H, Hfaeidh N, Bouoni Z, Sakly M, Ben Rhouma K. Protective effect of Opuntia ficus indica f. Inermis prickly pear juice upon ethanol-induced damages in rat erythrocytes. Alcohol. 2012;46:235-43.

20. Uchida K. Role of reactive aldehyde in cardiovascular diseases. Free Rad Biol Med. 2000:28:1685-96

21. Jabri MA, Rtibi K, Tounsi H, Hosni K, Marzouki L, Sakly M, Sebai H. Fatty acids composition and mechanism of protective effects of myrtle berries seeds aqueous extract against alcohol-induced peptic ulcer in rat. Can J Physiol Pharmacol. 2017:95:510-21.

22. Jabri MA, Rtibi K, Tounsi H, Hosni K, Souli A, El-Benna J, Marzouki L, Sakly M, Sebai H. Myrtle berries seeds aqueous extract inhibits in vitro human neutrophils myeloperoxidase and attenuates acetic acid-induced ulcerative colitis in rat. RSC Adv. 2015;5:64865-77.

23. National Research Council. Guide for the care and the use of laboratory animals, vol. 20. Bethesda: National Institute of Health; 1985. p. 85.

24. Penha-Silva N, Arvelos LR, Cunha CC, Aversi-Ferreira TA, Gouvêa-e-Silva LF, Garrote-Filho MS, Finotti CJ, Bernardino-Neto M, de Freitas Reis FG. Effects of glycerol and sorbitol on the thermal dependence of the lysis of human erythrocytes by ethanol. Bioelectrochemistry. 2008;73:23-9.

25. Draper $\mathrm{HH}$, Hadley M. Malondialdehyde determination as index of lipid peroxidation. Methods Enzymol. 1990;186:421-31.

26. Sedlak J, Lindsay RH. Estimation of total, protein bound, and non-protein sulfhydryl groups in tissue with Ellman's reagent. Anal Biochem. 1968:25:192-205.

27. Ellman GL. Tissue sulfhydryl groups. Arch. Biochem Biophys. 1959;82:70-7.

28. Misra HP, Fridovich I. The role of superoxide anion in autoxidation of epinephrine and a simple assay for superoxide dismutase. J Biol Chem. 1972;247:3170-5.

29. Aebi H. Catalase in vitro. Methods Enzymol. 1984;105:121-6.

30. Flohé L, Günzler WA. Assays of glutathione peroxidase. Methods Enzymol. 1984;105:114-21.

31. Hartree EF. Determination of protein: a modification of the Lowry method that gives a linear photometric response. Anal Biochem. 1972;48:422-7.

32. Dingeon B, Ferry JP, Roullet A. Automatic assay of blood sugar by Trinder's method. Ann Biol Clin (Paris). 1975;33:3-13.

33. Paya $M$, Halliwell $B$, Hoult JR. Interactions of a series of coumarins with reactive oxygen species. Scavenging of superoxide, hypochlorous acid and hydroxyl radicals Biochem Pharmacol. 1992;44:205-14.

34. Marklund SL, Marklund G. Involvement of the superoxide anion in the autooxidation of pyrogallol and a convenient assay for superoxide dismutase. Eur J Biochem. 1974:47:469-74.

35. Maturu P, Reddy VD, Padmavathi P, Varadacharyulu N. Ethanol induced adaptive changes in blood for the pathological and toxicological effects of chronic ethanol consumption in humans. Exp Toxicol Pathol. 2012:64:697-703.

36. Hou SZ, Su ZR, Chen SX, Ye MR, Huang S, Liu L, Zhou H, Lai XP. Role of the interaction between puerarin and the erythrocyte membrane in puerarininduced hemolysis. Chem Biol Interact. 2011;192:184-92. 
37. Chikezie PC, Uwakwe AA. Membrane stability of sickle erythrocytes incubated in extracts of three medicinal plants: Anacardium occidentale, Psidium guajava, and Terminalia catappa. Pharmacogn Mag. 2011;7:121-5.

38. Paraiso LF, Gonçalves-E-Oliveira AF, Cunha LM, de Almeida Neto OP, Pacheco AG, Araújo KB, Garrote-Filho MD, Bernardino Neto M, Penha-Silva $N$. Effects of acute and chronic exercise on the osmotic stability of erythrocyte membrane of competitive swimmers. PLoS One. 2017;12:e0171318.

39. Mascarenhas Netto Rde C, Fabbri C, de Freitas MV, Bernardino Neto M, Garrote-Filho MS, Lacerda MV, Lima ES, Penha-Silva N. Influence of plasmodium vivax malaria on the relations between the osmotic stability of human erythrocyte membrane and hematological and biochemical variables. Parasitol Res. 2014;113:863-74.

40. Mpiana PT, Ngbolua KN, Bokota MT, Kasonga TK, Atibu EK, Tshibangu DS, Mudogo V. In vitro effects of anthocyanin extracts from Justicia secunda Vahl on the solubility of haemoglobin $\mathrm{S}$ and membrane stability of sickle erythrocytes. Blood Transfus. 2010;8:248-54.

41. Zavodnik IB, Piletskaia TP, Stepuro II. Kinetics of ethanol-induced lysis of human erythrocytes. Biofizika. 1994;39:33-1039.

42. Belkhiri F, Baghiani A, Zerroug MM, Arrar L. Investigation of antihemolytic, xanthine oxidase inhibition, antioxidant and antimicrobial properties of Salvia verbenaca L. aerial part extracts. Afr J Tradit Complement Altern Med. 2017; 14:273-81.

43. Assadpour S, Nabavi SM, Nabavi SF, Dehpour AA, Ebrahimzadeh MA. In vitro antioxidant and antihemolytic effects of the essential oil and methanolic extract of Allium rotundum L. Eur Rev Med Pharmacol Sci. 2016;20:5210-5.

44. Kandikattu HK, Rachitha P, Krupashree K, Jayashree GV, Abhishek V, Khanum F. LC-ESI-MS/MS analysis of total oligomeric flavonoid fraction of Cyperus rotundus and its antioxidant, macromolecule damage protective and antihemolytic effects. Pathophysiology. 2015;22:165-73.

45. Davis JS, Waters JA, Parmar SS. Anti-inflammatory, antiproteolytic, and antihemolytic properties of pyrrole carboxylic acids. Pharmacology. 1981;23:287-92.

46. Parmar SS, Raman K, Kumar S, Brumleve SJ. Relationship between antiinflammatory, antiproteolytic and antihemolytic properties of some newer substituted S-triazole-2-thiols. Proc West Pharmacol Soc. 1978;21:223-7.

47. Rajasinghe $H$, Jayatilleke $E$, Shaw S. DNA cleavage during ethanol metabolism: role of superoxide radicals and catalytic iron. Life Sci. 1990;47: 807-14.

48. Nordmann R, Ribiere $\mathrm{C}$, Rouach $\mathrm{H}$. Alcool et radicaux libres : données actuelles. Med Sci (Paris). 1988;4:336-45.

49. Ramani R, Ramachandran A, Ravindran S, Kurian GA. Erythrocyte membrane bound ATPase and antioxidant enzyme changes associated with vascular calcification is reduced by sodium thiosulfate. Indian J Clin Biochem. 2017;32:487-92.

50. Singh AK, Garg G, Singh S, Rizvi Sl. Synergistic effect of rapamycin and metformin against age-dependent oxidative stress in rat erythrocytes. Rejuvenation Res. 2017;20:420-9.

51. Nordmann R, Ribiere C, Rouach $\mathrm{H}$. Implication of free radical mechanisms in ethanol-induced cellular injury. Free Rad Biol Med. 1992;12:219-40.

52. Wu D, Cederbaum Al. Ethanol and arachidonic acid produce toxicity in hepatocytes from pyrazole-treated rats with high levels of CYP2E1 Mol Cell Biochem. 2000;204:157-67.

53. Kose K, Dogan P. Lipoperoxidation induced by hydrogen peroxide in human erythrocyte membrane. Protective effect of Ginkgo Biolabo extract (EGB761). J Int Med Res. 1995;23:1-8.

54. Hale JP, Winlove CP, Petrov PG. Effect of hydroperoxides on red blood cell membrane mechanical properties. Biophys J. 2011;101:1921-9.

55. Jabri MA, Marzouki L, Sebai H. Ethnobotanical, phytochemical and therapeutic effects of Myrtus communis L. berries seeds on gastrointestinal tract diseases: a review. Arch Physiol Biochem. 2018; https://doi.org/10.1080/ 13813455.2017.1423504

56. Nève J. Optimisation of dietary intake of anti-oxidants. Nutr Clin Métabol. 2002;16:292-300.

57. Khoruts A, Stahnke L, Mcclain CJ, Logan G, Allen Jl. Circulating tumor necrosis factor, interleukin-1 and interleukin 6 concentrations in cirrhotic alcoholic patients. Hepatology. 1991;13:267-76.

58. Taieb J, Mathurin P, Elbim C, Cluzel P, coll Arce-vicioso M et. Blood neutrophil functions and cytokine synthesis in severe alcoholic hepatitis. Effect of corticosteroids. J Hepatol. 2000;32:579-86.
59. Malby J, Wright S, Bird G, Sheron N. Chemokine levels in human liver homogenates : associations between GRO alpha and histopathological evidence of alcoholic hepatitis. Hepatology. 1996;24:1156-60.

60. Hill DB, Marsano LS, Mcclain CJ. Increased plasma interleukin-8 concentrations in alcoholic hepatitis. Hepatology. 1993;18:576-80.

61. Liu Y, Tian X, Gou L, Fu X, Li S, Lan N, Yin X. Protective effect of I-citrulline against ethanol-induced gastric ulcer in rats. Environ Toxicol Pharmacol. 2012;34:280-7.

62. Delarue J. Acides gras polyinsaturés et inflammation. Nutr Clin Métabol. 2001;15:172-6.

63. Calder P. Polyunsaturated fatty acids and inflammation. Prost Leuk Ess. 2006;75:197-202.

64. Jabri MA, Tounsi H, Rtibi K, Marzouki L, Sakly M, Sebai H. Ameliorative and antioxidant effects of myrtle berries seeds (Myrtus communis) extract during reflux-induced esophagitis in rats. Pharm Biol. 2016:54:1575-85.

65. Holmuhamedov E, Lemasters JJ. Ethanol exposure decreases mitochondrial outer membrane permeability in cultured rat hepatocytes. Arch Biochem Biophys. 2009;481:226-33.

66. Fromenty B, Mansouri A, Degoul F, Demeilliers C, Gaou I, Pessayre D. Ageing, alcohol and mitochondria. Gastroenterol Clin Biol. 2000;24:349-58.

67. Kim JS, He L, Lemasters JJ. Mitochondrial permeability transition: a common pathway to necrosis and apoptosis. Biochem Biophys Res Commun. 2003;304:463-70.

\section{Ready to submit your research? Choose BMC and benefit from:}

- fast, convenient online submission

- thorough peer review by experienced researchers in your field

- rapid publication on acceptance

- support for research data, including large and complex data types

- gold Open Access which fosters wider collaboration and increased citations

- maximum visibility for your research: over $100 \mathrm{M}$ website views per year

At BMC, research is always in progress.

Learn more biomedcentral.com/submissions 